\title{
Entrevista: 0 enfoque das políticas do SUS para promoção da saúde e prevenção das DCNT: do passado ao futuro
}

\author{
Interview: The approach by the Brazilian National \\ $\mathrm{H}$ ealth System to the health promotion and \\ prevention of Chronic Non-Communicable Diseases
}

Entrevistado:

Jorge José Santos Pereira Solla 1

Entrevistadores:

Laércio Joel Franco 2

Geniberto Paiva Campos 3

Carlos Alberto M achado 4

Organizadora: Ines Lessa 5

1 Secretaria de Atenção à Saúde, M inistério da Saúde. Esplanada dos M inistérios, Edifício Sede, 9o andar, bloco $\mathrm{G}$, sala 906 ,

70058-900, Brasília DF solla@saude.gov.br.

2 Faculdade de M edicina

de Ribeirão Preto,

Universidade de São Paulo.

3 Divisão de Doenças

Crônico-Degenerativas,

Ministério da Saúde.

4 Secretaria Estadual

de Saúde de São Paulo.

5 Instituto de Saúde

Coletiva, Universidade

Federal da Bahia.
As políticas e estratégias utilizadas e direcionadas para todos os níveis de prevenção das doenças crônicas não-transmissíveis (DCNT) são pouco abordadas na literatura científica nacional. Componentes desse grupo são desencadeantes das mais representativas causas de morte no Brasil, indiscriminadamente em todas as macrorregiões. Destacam-se especialmente a hipertensão arterial e o diabetes mellitus. Ambas produzem elevados custos com hospitalizações, incapacidade temporária ou permanente e invalidez. Suscitam questionamentos sobreo queforam, o que são e o que se pretende com as políticas e práticas direcionadas para soluções adequadas, extensivamente viáveis no território nacional e capazes de produzir resultados socialmente compensatórios. É essencial transpor e disponibilizar essas informações dire tamente do mais importante responsável pela saúde pública no País - o M inistério da Saúde para veículo científico apropriado e acessível.

0 entrevistado sobre essetema é um representante oficial do Governo. Os entrevistadores são profissionais que lidaram em algum momento ou ainda lidam com o problema sob enfoque.

A entrevista foi organizada pela editora deste número especial sobre DCNT da Revista Ciência \& Saúde Coletiva (IL). M etodologicamente foram convidados quatro entrevistadores para abordagens - um sobre o câncer e três sobre doen- ças cardiovasculares e/ ou diabetes, sendo prérequisito atuação anterior ou atual de direção ou coordenação de programas específicos para DC$N T$, em qualquer das esferas governamentais. D ois convidados para inquirir sobre o câncer não tiveram disponibilidade para participar, restringindo-se, involuntariamente, a entrevista às doenças cardiovasculares e ao diabetes. Cada entrevistador recebeu informação sobre o direcionamento das questões: políticas e programas para DCNT anteriores, atuais e perspectivas futuras. A proposta foi de quatro questões por entrevistador, com possibilidade de desdobramentos. Questionamentos e respostas foram encaminhados via eletrônica. De posse das respostas, os entrevistadores, opcionalmente, poderiam comentá-las, dando-se conhecimento ao entrevistado. U ma vez completada e organizada a entrevista, todos a receberam para aprovação das corr reções efetuadas, mantendo-se na íntegra os conteúdos dos autores. As questões ( $Q$ ) e comentários, quando efetuados, encontram-se identificados por números e por iniciais dos entrevistadores (Laércio Franco - LF; Geniberto Campos - GC; e Carlos M achado - CM ), acompanhados das respectivas respostas do dr. Jorge Solla (JS).

As questões foram agrupadas sob tópicos, situando-as no contexto das políticas/programas, finalizando com al guns comentários da organizadora (IL). 


\section{Programas educativos}

Q1 - LF Com a crescente prevalência de diabe tes, há necessidade de atendimento aos casos de menor complexidade não só por clínicos gerais, como também por uma equipe de saúde mínima (médico e enfermeiro) para desenvolver atividades educativas essenciais ao melhor controle metabólico do paciente, promover adesão ao tratamento e prevenção de complicações específicas.

Como manter um programa de educação permanente para capacitação e atualização dos mé dicos que atuam nas unidades básicas de saúde? JS O M inistério da Saúde desenvolveu um processo de capacitação para profissionais da rede básica de todo o Brasil com participação de 862 médicos e 1.162 enfermeiras; muita gente está capacitada pelos próprios Estados e/ou municípios. Sem dúvida que isso nunca se esgota. Vamos fomentar essas capacitações através dos Pólos de Educação Permanente nos Estados e municípios e criar mecanismos de educação a distância. Esperamos contar com a parceria das sociedades científicas.

Comentário LF 0 número de médicos e enfermeiros citado pelo dr. Solla para todo o Brasil mostra a baixa cobertura desses programas de treinamento. As propostas de megatreinamentos, seja através dos Pólos de Capacitação seja através de sociedades científicas, têm se mostrado pouco eficazes. Isto fica mais evidente quando o treinamento é realizado em local distante daquele do trabalho; quem pode se deslocar geralmente são os profissionais que não estão envolvidos com a assistência. Não existenenhuma proposta de treinamento in loco, atingindo realmente a população que deveria ser 0 objeto do treinamento. Existem experiências com esse tipo de abordagem, embora limitadas, que mostraram ser muito superiores aos treinamentos fora do local de trabalho.

JS 0 número de médicos e enfermeiros se refere aos que iniciaram e concluíram treinamento em 2004. Até o final deste ano serão 3.707 profissionais capacitados. Em 2001 (primeira fase) foram capacitados multiplicadores através das coordenações estaduais e sociedades científicas com apoio do Ministério da Saúde. Entre 2002 e 2003 foram capacitados 4.729 profissionais (médicos e enfermeiros). Já está sen do fechada a programação para o próximo ano. É importante ressaltar que estes treinamentos estão sendo feitos de forma descentralizada em diversos municípios, contando com os multiplicadores capacitados durante a primeira fase. No momento está em elaboração uma estratégia de educação a distância.

Q2 - LF Como fazer para que o enfermeiro participe mais ativamente das atividades assistenciais e educativas, visto que atualmente se envolve quase que apenas com atividades administrativas?

JS Os enfermeiros que atuam nas equipes do PSF participam ativamente das ações de saúde junto com o médico e outros componentes da equipe. 0 desafio é fazer esse trabalho nas demais unidades e equipes de saúde. Tem-se observado um aumento importante do desenvolvimento de atividades assistenciais pelos enfermeiros.

Comentário LF 0 problema básico é que a formação do enfermeiro atualmente concentra-se mais nas atividades administrativas. As atividades assistenciais foram delegadas para o auxiliar de enfermagem. Além de um trabalho junto com os centros formadores de enfermeiros, 0 mercado necessita passar a valorizar e dar importância às atividades educativas e assistenciais. JS A participação de enfermeiros em atividades assistenciais tem crescido nos últimos anos no SUS, especialmente nas equipes de saúde da família. N estas atividades destacam-se as ações de pré natal, acompanhamento do crescimento e desenvolvimento infantil, controle de hipertensão e diabetes, acompanhamento de casos de tuberculose e hanseníase, entre outros. As lacunas de formação demandam que as capacitações desenvolvidas tenham como alvo tanto médicos quanto enfermeiros.

Q3 - LF Como valorizar e prestigiar as ações educativas em saúde, no caso particular em diabetes, tendo em vista a baixa remuneração desses procedimentos?

JS Os repasses federais do SU S para atenção básica não são mais efetivados a partir de valores de procedimentos de uma tabela. São definidos por valores per capita (Piso de Atenção Básica Fixo), incentivos relacionados à implantação de ações e serviços e a atuação de equipes multiprofissionais (Piso deAten ção Básica Variável). N este último estão incluídos os repasses relativos a Agentes Comunitários de Saúde e a Equipes de Saúde da Família. Associado a isto é importante lembrar que hoje a atenção básica é quase totalmente realizada a partir de serviços públicos de saúde, gerenciados pelos municípios, onde os profissionais são assalariados desta esfera de governo ou cedidos por outra. Quanto 
aos procedimentos especializados (ambulatoriais e hospitalares), registramos que no ano de 2003 o M inistério da Saúde procedeu a diversos reajustes de valores das tabelas SI A/SIH . Entre eles destacamos: o reajuste dos valores das consultas médicas especializadas nas unidades públicas, correspondendo a um impacto superior a 500 milhões de reais por ano (em 2002 houve um aumento apenas para as consultas realizadas em unidades privadas contratadas/conveniadas - mais de $80 \%$ das consultas médicas especializadas realizadas na rede SUS são feitas pela rede pública); aumento dos valores de vários procedimentos de diagnose (entre eles as ultra-sonografias, EEG, ECG, endoscopias, biópsias, anatomia patológica, etc.) e reajustes nos valores de quase 300 procedimentos de internações hospitalares (aqueles com maior defasagem entre 0 valor de tabela e 0 custo). Estamos preparando novos reajustes para este ano que irão melhorar a remuneração pelo SUS, diminuindo o grande fosso entre os valores da tabela e o custo, especialmente nos procedimentos de média complexidade. A defasagem existente no início de 2003 só poderá ser resolvida em movimentos anuais de reajustes progressivos em função das distâncias que chegaram a ser permitidas.

Comentário LF Embora os repasses federais do SUS não sejam mais efetivados a partir de valores de procedimentos de uma tabela, as ações educativas em saúde não se colocam entre as principais prioridades nos serviços de saúde, em particular nas unidades básicas de saúde do SUS. Apesar de haver um consenso sobre a importância das ações de educação em saúde, ainda não existe uma proposta para valorizá-las e prestigiá-las.

JS Valorizar determinado tipo de ações não passa necessariamente por estabelecer valores para pagamento por produção. A incorporação das ações de educação em saúde na agenda de trabalho das equipes de saúde da família e nos protocolos assistenciais são formas de ampliar sua oferta. Além da atenção básica que não tem mais repasses federais estabelecidos por pagamento por produção, o Ministério da Saúde vem implantando progressivamente modalidades de pagamento global nos Centros de Referência em Saúde do Trabalhador, Centros de Especialidades Odontológicas, Serviço de Atendimento M óvel de Urgência (SAMU 192) e através da contratualização dos hospitais universitários.
Q4 - CM Qual a prioridade que está sendo dada ao Programa de Educação Permanente em Hipertensão e Diabetes, que era uma das fases mais importantes do Plano de Reorganização da Atenção à Hipertensão Arterial e ao Diabetes M ellitus? JS Entendo que é prioridade a capacitação dos profissionais e a educação permanente e continuada em serviço, que atenda às constantes demandas de avanço tecnológico nessa área, não só de conteúdo como de estratégias de ação. Como já referido anteriormente, foram treinados profissionais em todo o Brasil eessa capacitação deverá ser implementada. M ecanismos de educação permanente a distancia e em serviço estão sendo discutidos. Está em curso o processo de implantação de 70 Pólos de Educação Permanente do SUS que terão em sua agenda, entre outras prioridades, a programação das atividades de educação permanente em hipertensão e diabetes.

Q5 - LF Como desenvolver e estimular, no SUS, atividades voltadas a modificações no estilo de vida da população?

JS Esteé um desafio mundial. Informar e sensibilizar é muita coisa, mas ainda não é o bastante; é necessário que cada indivíduo e as comunidades usem essa informação no sentido de, de fato, ter a disposição de mudar hábitos de vida arraigados e que inclui prazer, cultura, etc. A população mundial está ficando obesa, sedentária, o que vem aumentando a morbidade por doenças crônicas. A mortalidade até que diminuiu devido ao maior acesso a bens e serviços, incluindo aí os de saúde, e ao avanço tecnológico que salva vidas. Mas a morbidade avança a passos largos - mais gente vivendo com mais doença crônica. É necessário que governos e sociedade se unam para quebrar esse ciclo vicioso, paradoxalmente, um fruto da moderna civilização.

As estratégias passam não só pelos serviços de saúde, mas, principalmente, pela escola, mídia, informação e conscientização em larga escala e até medidas legislativas e econômicas. Vamos deixar de lado os aspectos fundamentalistas de proibições e castigo, mas são necessárias medidas enérgicas e de muita informação para reverter esse quadro maléfico para as sociedades, impossível de ser suportado por qualquer sistema de saúde no mundo. N ão podemos legar esse ônus às futuras gerações. A OM S lançou para consulta dos países-membro a estratégia global de Alimentação Saudável eAtividade Física que será tema principal da 56a 
Conferência Mundial de Saúde. 0 M inistério da Saúde (M S) aderiu a essa idéia e vai estimular os planos nacional e setoriais com as recomendações da estratégia, recomendações estas já bastante conhecidas e indicadas pelos especialistas eque têm inúmeras evidências científicas que as comprovam.

O difícil são as estratégias para implementar essas recomendações num país diverso cultural e socialmente como o nosso. Daí a importância das parcerias para a ação - organismos nacionais e internacionais, rede de países, todos devem se juntar nessa tarefa. Devemos incluir nesse esforço a população atendida por planos privados, as estatais, enfim, todo o setor saúde público e privado, governamental ou não.

Estamos com um Grupo no M S trabalhando em um projeto para escolas, junto com 0 $M E C$ e com o M inistério dos Esportes, no sentido de tornar os equipamentos urbanos (praças, ruas, jardins, etc.) mais disponíveis para o cidadão e criar uma "cultura" de estímulo à atividade física.

Temos uma Política de Segurança Alimentar e programas oficiais de combate à fome. Deve-se combater a fome com o conceito de segurança alimentar - alimento saudável que não gere doença. 0 M S participa do programa através da área de Alimentação, Nutrição e Segurança alimentar do DAB/SAS. Existem ações que são individuais, mas já está comprovado que ações coletivas dão resultados muito mais persistentes e eficazes.

Comentário LF Que o problema é difícil e complexo não existem dúvidas, senão seria facilmente resolvido. As parcerias com as diversas instâncias, públicas e privadas, são fundamentais. Entretanto, falta uma proposta concreta dos órgãos governamentais.

JS Existem diversas propostas em curso e outras em fase de negociação com os representantes das secretarias estaduais e municipais de saúde. A proposta da Estratégia Global para a Promoção da Alimentação Saudável, Atividade Física e Saúde foi apoiada pelo Brasil eapresenta-se como uma oportunidade singular para a formulação e implementação de uma linha de ação efetiva para reduzir substancialmente as mortes e doenças em todo o mundo. Pressupõe que para modificar os padrões de alimentação e de atividade física da população são necessárias estratégias sólidas e eficazes acompanhadas de um processo de permanente vigilância e de avaliação de impacto das ações planejadas. Foi definida a construção de uma agenda de trabalho intersetorial para a promoção da alimentação saudável, que integra os principais setores envolvidos com a proposta, bem como a implementação de linhas de trabal ho na perspectiva de "selar" a identidade brasileira na proposição. N esta agenda foram relacionados três eixos estratégicos de atuação: iniciativa nacional de incentivo ao consumo de verduras, legumes e frutas; ações de promoção da alimentação saudável nas escolas (espaço saudável de formação de hábitos); e regulamentação em relação à alimentação no que diz respeito ao marketing, à publicidade voltada ao público infantil e à comercialização, principalmente nas escolas. 0 M inistério da Saúde instituiu, em setembro de 2004, Comissão Técnica, com a finalidade de proceder à implantação da Estratégia Global sobre Alimentação, Atividade Física e Saúde da Organização M undial da Saúde. A Política Nacional deAlimentação e Nutrição integra o Plano Nacional de Saúde, compondo o conjunto das políticas de governo voltadas para a concretização do direito humano universal à alimentação e nutrição adequadas. Além disto, considerando a necessidade de ampliar a resolutividade e a qualidade da atenção básica, com ênfase na estratégia Saúde da Família e apoiado nas experiências de vários municípios o M inistério da Saúde estará em 2005 incentivando a criação de Núcleos de Saúde Integral. Esses núcleos serão compostos por três modalidades - atividade física e saúde, saúde mental, e reabilitação - , podendo contribuir na implementação de práticas que corroboram para a construção do cuidado em saúde, na perspectiva do autocuidado, promover a autonomia dos usuários e famílias e fortalecer a cidadania e ampliar o acesso às ações de Saúde M ental, Reabilitação e de Atividade Física e práticas corporais.

\section{Políticas de medicação/tratamento, controle e prevenção}

Q6 - LF As medicações utilizadas para o controle do diabetes são de uso contínuo. Entretanto, os municípios recebem do governo federal cotas de medicação insuficientes, geralmente atingindo $30 \%$ das necessidades reais. Tendo em vista as limitações orçamentárias dos municípios, pergunta-se: Poderia existir um sistema que possibilitasse uma cobertura de $100 \%$ das necessidades de medicação antidiabética para os pacientes atendidos pelo SUS? 
JS A Política Nacional de Assistência Farmacêutica foi pactuada com Estados e municípios no sentido de co-participação no financiamento de um elenco de medicamentos da rede básica que atendesse os principais agravos desse nível de atenção. De fato, alguns municípios e mais ainda alguns Estados vêm se retraindo desse financiamento, ficando só a parcela do gestor federal. Contudo não podemos afirmar que recebem do governo federal $30 \%$ das necessidades. Toda a oferta de insulina já é assegurada pelo M inistério da Saúde - temos ainda problemas na distribuição entre Estados e municípios em determinados momentos. Existem hoje cinco mecanismos diferentes no SUS para assegurar a oferta de medicamentos visando ao controle de hipertensão e diabetes: o repasse da assistência farmacêutica básica feito pelo M inistério da Saúde ( $R \$ 1,00$ habitante/ano, sendo que este ano passou para $R \$ 2,00$ habitante/ano para os municípios inseridos no Programa Fome Zero), a contrapartida estadual, a contrapartida municipal, os kits distribuídos pelo M inistério da Saúde para as equipes de saúde da família e as remessas do Ministério para municípios que alimentam o sistema Hiperdia. Em muitas situações, Estados e Municípios não cumprem suas contrapartidas ou as aplicam para aquisição de outros medicamentos da lista da assistência farmacêutica básica, deixando apenas o fornecimento de medicamentos para controle de hipertensão arterial e diabetes por conta do fornecimento direto do M inistério da Saúde. Cabe ressaltar que esses kits não são programados para atender $100 \%$ das necessidades e sim para complementar a compra feita com os recursos pactuados pelas três esferas de governo para a Assistência Farmacêutica Básica.

Por determinação do M inistro da Saúde, que tem desde 0 ano passado demonstrado preocupação com este quadro, o M inistério irá renegociar com Estados e municípios a política de assistência farmacêutica básica. A proposta que está sendo elaborada prevê a compra direta pelo MS da totalidade dos medicamentos previstos pelo Plano Nacional de Atenção ao DM e HA (Hidroclorotiazida, Propranolol, Captopril, Glibenclamida e M etformina, além da Insulina NPH), em quantidade necessária para cobrir a população usuária do SU S, portadora desses agravos crônicos e cadastrada e acom panhada pela rede. Isso vai ser gradativo, já que precisamos ter mecanismos de controle da utilização desses medicamentos na rede básica de todo 0 Brasil para monitorar essa ação que custa mui- to para o SUS em termos financeiros, mas que pode representar um enorme ganho social e econômico em médio prazo pelas complicações que serão evitadas com o controle mais rigoroso da glicemia e da pressão arterial. N esta nova proposta, o M inistério da Saúde ficaria encarregado de comprar e fornecer os medicamentos para controle de hipertensão e diabetes, para tratamento de asma brônquica, tuberculose, hanseníase, malária, leishmanioses, reposição de nicotina, e os contraceptivos; os Estados assumiriam os antibióticos da lista básica e os medicamentos da lista de saúde mental, e os municípios ficariam com a responsabilidade de adquirir os demais medicamentos da lista básica (antitérmicos, analgésicos, antiparasitários e outros). Cabe lembrar que esta proposição depende de negociação com o Conselho Nacional de Secretários de Saúde (CONASS) e com o Conselho Nacional de Secretários M unicipais de Saúde (CONASEM S) e aprovação na Comissão Intergestores Tripartite (CIT) para sua implantação.

Além disso, cabe registrar que já entraram em operação as primeiras farmácias populares disponibilizando, entre outros tipos de fármacos, medicamentos para controle de hipertensão arterial e diabetes a preços reduzidos (apenas repondo os custos de produção).

Comentário LF Vincular o fornecimento de medicação ao cadastro dos pacientes é subestimar a real necessidade. 0 Hiperdia ainda tem uma cobertura muito baixa e vai demorar para representar a real necessidade. $\mathrm{A}$ isto deve ser acrescido o fato de que cidadãos, não-usuários do SUS, buscam os serviços públicos para o fornecimento de medicações. 0 próprio governo federal tem ações não consistentes com as propostas do SU S, como a criação das farmácias populares.

JS Cada município tem autonomia para adotar estratégias próprias para cadastramento e vinculação desses indivíduos à Unidade Básica de Saúde, especialmente através das equipes de saúde da família. 0 cadastramento dos pacientes possibilita aos gestores federais, estaduais e municipais do sistema de saúde planejarem os recursos e as ações necessárias para 0 atendimento desta clientela, pois o mesmo permite a quantificação e a estratificação desses pacientes e como estão sendo acompanhados, assim como o levantamento do perfil epidemiológico, possibilitando conhecer o comportamento dos fatores de risco para as duas patologias e as doenças concomitantes. Quanto ao forneci- 
mento de medicamentos cabe registrar que a assistência farmacêutica não pode ser concebida como simples atendimento da demanda de medicamentos gerada nos serviços, mas sim como parte da Política Nacional de Saúde, envolvendo um conjunto de ações voltadas à promoção, proteção e recuperação da saúde, tendo 0 medicamento como insumo essencial. 0 Programa Farmácia Popular tem como objetivo estabelecer alternativas de ampliação de acesso da população aos medicamentos por meio de ações que articulem os setores público e privado: a criação de uma rede de farmácias públicas (Farmácia Popular do Brasil). Já estão em funcionamento (outubro/2004) 26 farmácias: 16 em São Paulo, cinco em Salvador, duas no Rio deJaneiro, uma em Goiânia, uma em Vitória da Conquista (BA) e uma em Caxias do Sul (RS). Entre os dez medicamentos mais procurados nas farmácias populares, seis são indicados para o tratamento de hipertensão, dois para o tratamento de diabete e dois utilizados para tratar úlceras gástricas; a venda de medicamentos com preços subsi diados na rede privada de farmácias (11 medicamentos essenciais para tratamento da hipertensão e do diabetes); e a redução de ICMS de medicamentos de uma lista selecionada 0 governo incluiu na reforma tributária a redução do ICMS de uma lista de medicamentos, com a finalidade de redução dos preços, tendo como previsão inicial da abrangência da ação uma redução de $12 \%$ a $15 \%$ nos preços de cerca de 2.800 medicamentos. 0 impacto nos preços deve ocorrer a partir de janeiro de 2005, após a regulamentação da Reforma Tributária. Paralelo à implantação dessas ações, o governo federal vem, nesta gestão, realizando um aumento substancial nas compras de medicamentos para distribuição gratuita através da rede SU S. Em 2002 foram gastos cerca de 2,5 bilhões de reais com medicamentos (compra direta e repasse de recursos para estados e municípios). Em 2004 este valor será superior a 3,5 bilhões de reais. Os gastos com medicamentos excepcionais quase dobraram entre 2002 e 2004. Os investimentos do M inistério da Saúde em laboratórios públicos foram da ordem de 20 milhões somando o efetivado nos anos de 2001 e 2002. Em 2004 estão sendo disponibilizados 80 milhões para tal finalidade. Cabe ainda destacar que foi adquirida uma nova unidade de produção de medicamentos no Rio de Janeiro que permitirá aumentar em quatro vezes a produção efetivada por Farmanguinhos.
Q7 -GC Na sua opinião, a implantação e o desenvolvimento do SUS no Brasil, nas duas últimas décadas, tornou mais eficaz o sistema de atendimento nas redes primária e secundária no País?

JS Sem dúvida, houve ampliação importante no acesso, mudanças substanciais na rede básica com a implantação da estratégia de saúde da família e aumento da capacidade diagnóstica e terapêutica da rede. Contudo, ainda é necessário continuar investindo no aumento da oferta e na qualificação da atenção prestada. Isso implica novas equipes de saúde da família, aumento da oferta de atenção de média complexidade, integração das diversas ações em linhas de cuidado, aumento da disponibilidade de medicamentos na rede, criação de capacidade de regulação do sistema, entre outras ações prioritárias.

Q8 - LF 0 SUS deve proporcionar material para automonitoramento da glicemia para os portadores de diabete?

JS 0 automonitoramento da glicemia em diabéticos é estratégia fundamental para o controle adequado das taxas de glicose e mecanismo importante de adesão ao tratamento; isso écrucial para o controle da doença e para evitar as complicações. Sem dúvida que requer muita informação e educação do paciente por parte da equipe e ajuda da família para que isso ocorra, coisa não muito fácil nesse Brasil de tantas disparidades. São Paulo e o DF já possuem leis estaduais que obrigam o poder público a fornecer os insumos - glicosímetro e fitas reagentes para pacientes que queiram e estejam capacitados para fazer o automonitoramento. A manutenção das fitas acarreta custos, que freqüentemente muitas famílias não conseguem absorver. Existe um projeto de lei federal, aprovado no Senado, com parecer favorável do M inistério da Saúde, ora em tramitação na Câmara dos Deputados, que trata da obrigatoriedade de 0 SUS proporcionar estes materiais aos pacientes. Devemos nos preparar para essa obrigação que trata de atender direito à saúde, mas vamos pactuar com estados e municípios a co-participação no financiamento. Por outro lado temos que capacitar nossas equipes, e estimular e capacitar os portadores de diabetes para 0 automonitoramento da glicemia.

Comentário LF Embora haja leis estaduais e projeto de lei federal, ainda não existe uma definição de onde sairá o recurso para compra de tiras reagentes e glicosímetros para a automonitorização domiciliar da glicemia. Nem mes- 
mo critérios para a distribuição desse material foram desenvolvidos.

JS Da mesma forma que para os medicamentos da lista básica está sendo negociada entre o M inistério da Saúde, o Conass e o Conasems uma proposta para o fornecimento de insumos para a rede básica entre eles glicosímetros e fitas reagentes. Cabe lembrar que o SU S é construído pelas três esferas de governo de forma compartilhada e dividindo entre si responsabilidades, não podendo a construção das políticas de saúde ser feita de forma unilateral e impositiva. Pe lo menos, na atual gestão do M inistério da Saúde, esta construção é feita de forma pactuada e incluindo todos os atores envolvidos (gestores, prestadores de serviço, entidades de profissionais e de usuários) e passando necessariamente por aprovação da Comissão Intergestores Tripartite e do Conselho Nacional de Saúde.

Q9 - CM A hipertensão arterial e o diabetes mellitus e suas complicações constituem um grande percentual da demanda nas aproximadamente 40.000 Unidades Básicas de Saúde (UBSs) do País.

0 senhor não acha que um programa de hipertensão e diabetes poderia ser uma estratégia complementar ao Programa de Saúde da Família (PSF) na organização da rede básica?

JS $A$ atenção básica à hipertensão arterial e ao diabetes mellitus faz parte das ações desenvolvidas pelas equipes do Programa de Saúde da Família, incluindo as ações de promoção, prevenção e assistência. Entendo que a equipe do PSF com área geográfica definida e clientela adstrita, representa o modelo ideal para Atenção Básica à Saúde, sobretudo no que diz respeito a permitir maiores possibilidades para 0 diagnóstico precoce e melhorar as condições para 0 adequado acom panhamento e controle de doenças crônicas como a hipertensão arterial e o diabetes mellitus. É preciso lembrar que importantes estudos realizados no Brasil nos anos 90, entre eles o realizado em Pelotas por docentes da UFPEL e o efetivado pela Unifesp, em São Paulo, mostraram a importância fundamental do diagnóstico precoce e do acompanhamento pelo mesmo profissional de saúde, para o sucesso no controle dos níveis tensionais. 0 trabalho da equipe multidisciplinar e do ACS facilita muito as ações de educação em saúde, atividades de grupo, ações comunitárias e o monitoramento dos portadores de forma mais adequada, propiciando a adesão do paciente ao tratamento (medicamentoso ou não), grande desafio da atenção às DCNT. Também na Atenção Básica tradicional, na qual não existe PSF, essas ações estão sendo organizadas e a Norma O peracional de Assistência à Saúde (NOAS) define a responsabilidade de Estados e municípios no controle da HA e DM . Muito ainda tem de ser feito nessa área, não temos dúvida, mas é prioridade do M S, na medida em que as DCNT e em especial a HA e DM , diretamente ou por suas complicações, representam a maior causa de morbi-mortalidade no mundo e também no Brasil, com enorme custo social e financeiro para o SUS.

Q10 - LF Atualmente, além do aumento do número de casos de diabetes, observa-se também uma maior sobrevida desses pacientes. $\mathrm{A}$ maior duração da sobrevida com diabetes vem acompanhada de maior freqüência de complicações crônicas da doença, principalmente nos pacientes com controle inadequado. Isto traz repercussões para o sistema de saúde quanto às necessidades de hospitalizações, de atendimentos e a procedimentos de maior complexidade, que nem sempre são disponíveis adequadamente na rede SUS. Além disso, para alguns procedimentos existe certa discriminação para o portador de diabetes.

Como poderia ser diminuída a fila de espera para procedimentos que impeçam ou limitem incapacitações, como a fotocoagulação por laser em casos de retinopatia proliferativa? Como se evitar a discriminação para o portador de diabe tes quanto a alguns tratamentos espeć́ficos, como programa de diálise e transplante renal?

JS Primeiro, em relação à fotocoagulação a laser para casos de retinopatia diabética cabe ressaltar que todos os procedimentos deste tipo pagos pelo SUS estão fora dos limites financeiros de Estados e municípios. Com vistas a estimular a ampliação de sua oferta, iniciamos ano passado uma avaliação da oferta deste procedimento e dos demais feitos em regime de "mutirão" - cirurgias de catarata, próstata e varizes. Iniciaremos este ano mudanças neste âmbito, visando adequar melhor a oferta destes procedimentos, bem como ampliar a lista para outros procedimentos cirúrgicos de média complexidade, com demanda reprimida em cada região. Cabe lembrar que a fotocoagulação tem oferta ainda restrita a número limitado de serviços, com grandes lacunas regionais especialmente no Norte e N ordeste. Quanto à outra questão, está em curso uma redefinição das políticas de alta complexidade no SUS; no momento, entre 
outras, está sendo negociada na Comissão Intergestora Tripartite uma proposta de definição de diretrizes para atenção ao doente renal, fruto de debates iniciados no ano passado e baseada em produto de um grupo de trabalho montado pelo M inistério da Saúde, envolvendo gestores do SUS, sociedades de especialistas e representantes de prestadores de serviços e de usuários. É importante registrar que este grupo de trabalho verificou que $13 \%$ dos pacientes que realizam hemodiálise pelo SUS têm menos de 30 anos de idade. Além disso, em muitos municípios praticamente metade dos pacientes que realizam hemodiálise teve o diagnóstico de insuficiência renal estabelecido em serviços de urgência/emergência. O utro dado relevante é que vários municípios que dispõem de oferta de hemodiálise pelo SUS não oferecem consulta de nefrologia na rede. Estes e outros el ementos do diagnóstico do grupo de trabalho permitiram construir uma proposta que almejamos possa melhorar a assistência ao doente renal e contribuir para a redução da ocorrência deste problema de saúde, antecipando-se a ele através do controle dos seus principais determinantes. No tocante ao transplante renal, diversas medidas vêm sendo tomadas desde 0 ano passado para ampliar a oferta de transplantes na rede SUS. 0 Brasil já é o segundo país do mundo em realização de transplantes de órgãos e o primeiro em oferta pública. Contudo, temos uma demanda reprimida importante, especialmente para transplante renal e de córnea, e necessidade intensa de melhoria na captação e na qualidade do acompanhamento dos pacientes. No dia 15 de abril foi iniciado o Fórum Nacional de Transplantes (duas etapas: 15 a 17 de abril e 13 a 15 de maio de 2004), que tem como objetivo avaliar e rever a política de transplantes no SUS. Precisamos também melhorar a gestão local do SUS, realizando a contratação da rede de serviços (apenas 13\% têm contrato ou convênio), definindo os compromissos dos prestadores de serviços e ampliando a capacidade de regulação, controle, avaliação e auditoria no SUS.

Comentário LF Diferentemente do que ocorre com a catarata, em que o procedimento "cura" o paciente com a cirurgia, na retinopatia diabé tica existe necessidade de um tratamento continuado. A penas uma sessão de laser não resolve o problema. Considero uma ingenuidade a proposta de resolver a espera para a fotocoagulação com laser através de mutirões. A fila que se observa nos mutirões apenas dá uma idéia da magnitude do problema. A sua solução requer uma abordagem mais complexa. 0 fato de 0 Brasil ocupar o segundo lugar em transplante renal e entre os que mais realizam hemodiálise deveria ser motivo, não de júbilo, mas de preocupação, pois traduz falência nos níveis primário e secundário da assistência à saúde. Baixa qualidade gera mau controle e conseqüentemente maior necessidade de atendimento às complicações. Além disso, os recursos financeiros e de pessoal para o atendimento de um caso de maior complexidade seriam suficientes para vários pacientes com menor complexidade. Deve haver um equilíbrio, sem maior prioridade para os casos mais complexos, mas sim para os casos em todos os estágios da doença. Do ponto de vista econômico, talvez os casos de menor complexidade atendidos em unidades deveriam receber maior atenção, para evitar que caminhem para a falência de órgãos e passem a necessitar de procedimentos de maior custo.

JS Primeiro quero lembrar que na nossa resposta apontamos a necessidade de expansão da oferta de procedimentos de fotocoagulação, que hoje é insuficiente e grandes diferenças na oferta entre as regiões. Quanto aos transplantes quero reiterar a informação que demos: o Brasil é o segundo país do mundo em realização de transplantes de órgãos e o primeiro em oferta pública; em nenhum momento afirmamos que - Brasil ocupa o segundo lugar em transplante renal. Quero ainda lembrar que o Ministério da Saúde publicou em junho deste ano a Política Nacional de Atenção ao Portador de Doença Renal, elaborada por um grupo de trabal ho com partici pação de representantes dos gestores do SUS, hospitais de referência e sociedade de especialistas, e aprovada pelo Consel ho Nacional de Saúde, definindo uma série de medidas a serem desenvolvidas em todos os níveis de atenção, desde a atenção básica até a alta complexidade ambulatorial e hospitalar (sugiro consultar as portarias no $1168 / G M$ e no $211 /$ SAS de 15/06/04).

Q11 - CM Como o governo pretende dar continuidade às ações do Plano de Reorganização da Atenção à Hipertensão Arterial e ao Diabetes M ellitus que vinham sendo implementadas?

JS O Plano Nacional de Atenção à Hipertensão Arterial e Diabetes M ellitus tem sido implementado com as ações a seguir descritas.

1. Capacitação de profissionais de saúde - a metodologia utilizada foi a de estudo de casos clínicos, antecedida por uma aula de atualização em HA e DM . Essa capacitação deverá pas- 
sar por um processo de atualização para incluir novas ações que vêm sendo discutidas na Secretaria de Atenção à Saúde do M inistério da Saúde. M étodos de educação a distância também deverão ser implementados para dar conta do número crescente de profissionais que demandam essa capacitação e, sobretudo, para qualificar 0 atendimento etorná-lo mais resolutivo.

2. Expansão da adesão e da cobertura do HIPERDIA - cadastramento e adesão vêm sendo ampliados; foi disponibilizado o módulo de acompanhamento que permitirá a desagregação dos dados por unidade de saúde/equipe, que assim poderá ter um histórico dos seus próprios pacientes. Tal medida poderá estimular 0 cadastramento e a qualidade da atenção. Hoje temos 5.239 municípios que aderiram ao Programa e informam acompanhar 7.800 .000 hipertensos e 2.700.000 diabéticos. Contudo, informando regularmente, temos 3.514 municípios contando com 2.670 .000 de pacientes acompanhados. Estes dados apontam a necessidade de capacitação e mecanismos de estímulo ao cadastramento e informação (alimentação do sistema) de forma mais regular.

3. Distribuição do kit de medicamentos padronizado para HA eDM - no primeiro semestre de 2003 houve uma interrupção na entrega devido a problemas de licitação (não programada adequadamente no final de 2002), produção (insuficiente em relação a alguns medicamentos) e distribuição dos medicamentos; essa entrega foi regularizada a partir de agosto, com exceção da M etformina, que só começou a ser entregue a partir de novembro de 2003. H oje a distribuição está regularizada. Não houve supressão de nenhum medicamento da lista. Anteriormente já comentamos sobre as propostas em debate para mudanças na aquisição e distribuição destes medicamentos.

4. Outras ações - publicação da pesquisa qualitativa das Campanhas de Detecção de H ipertensão Arterial e Diabetes M ellitus que ocorreram em 2001.

Q12 - GC Considerando a importância da detecção precoce da hipertensão arterial, diabetes mellitus, dislipidemias, entre outras, visando à prevenção secundária, pelo controle das doenças não-transmissíveis, pergunta-se qual a capacidade de resposta atual da rede primária de saúde a essas demandas?

JS A capacidade atual ainda é baixa, contudo tem aumentado progressivamente, apresentan- do um grande potencial em função de sua capilaridade e das mudanças que têm sido impulsionadas no modelo de atenção na rede básica. Já são mais de 180.000 agentes comunitários de saúde e quase 20.000 equipes de saú de da família em atividade. É grande o número de municípios que têm impulsionado mudanças no processo de trabalho nas unidades básicas com resultados positivos no aumento da detecção precoce e do controle destas patologias.

Q 13 - GC Avaliando o impacto epidemiológico das doenças não-transmissíveis e da Aids na morbi-mortalidade da população brasileira, como justificar os investimentos prioritários para o controle da Aids?

JS A prioridade no controle da Aids representa o resultado de diversos vetores, entre eles destacam-se a pressão da sociedade civil organizada e a ausência de respostas efetivas por parte da saúde suplementar e da medicina privada gerando forte demanda de segmentos socioeconomicamente mais diferenciados da população pela atenção através do SU S. Situação semelhante observa-se na terapia renal substitutiva e no transplante de órgãos. São três áreas de intervenção do SUS que alcançaram um bom padrão de oferta e qualidade. Esperamos poder estender este resultado para outras prioridades.

Q14 - GC Uma visão crítica eisenta do SU S permite detectar avanços que possibilitem ao sistema assumir um papel relevante no controle das doenças não-transmissíveis?

JS Com certeza, o SUS começa a atuar de forma mais efetiva no controle de doenças nãotransmissíveis, pautando a vigilância epidemiológica, atuando na área de segurança alimentar e colocando o controle de doenças crônicas, em especial a hipertensão ea diabetes, na ponta das prioridades da atenção à saúde. 0 controle destas doenças está na pauta do pacto da atenção básica, nas diretrizes da Norma de Atenção à Saúde (NOAS) , nas prioridades da assistência farmacêutica, etc.

Q 15 - CM Nas ações de implantação do Plano de Reorganização da Atenção à Hipertensão Arterial e ao Diabetes M ellitus existe um sistema de informação, o H iperdia, que além de ser um importante instrumento para o gestor planejar recursos para o atendimento dos hipertensos e diabéticos é, talvez, o único capaz de disponibilizar para o profissional que atua na 
Unidade Básica de Saúde (UBS) dados que possibilitem avaliar a qualidade da assistência.

Este sistema vai continuar a ser alimentado pelosmunicípios? Vai haver algum incentivo para isso?

JS Vai continuar sim e está sendo implementado. Como já referido, temos hoje um número grande de municípios que aderiram, mas um número menor que alimenta regularmente. Precisamos encontrar fórmulas de incentivar e ampliar essa informação. 0 Hiperdia é o único sistema de informação que está na WEB, fornecendo informações sobre fatores de risco, complicações e uso de medicamentos. Nenhum outro sistema do M S dá essas informações; mesmo com as restrições que temos da qualidade dessas informações e da cobertura diante do número de HA e DM estimados no País, temos quase três milhões de pacientes cadastradose sendo acompanhados. 0 sistema é novo, mas vamos implementar e estimular os municípios e as equipes para melhorar a cobertura, qualidade e continuidade da informação. 0 módulo de acompanhamento foi desenvolvido e está disponível. Sem dúvida que ações de capacitação serão imprescindíveis para dar conta destes desafios.

O M inistério da Saúde está desenvolvendo um sistema que vai agregar todos os que hoje são empregados na atenção básica à saúde, permitindo evitar sobreposição e duplicação das tarefas de registro de dados e ampliar as possibilidades de utilização das informações, possibilidade que hoje élimitada, uma vez que os sistemas de informação não se articulam; o Hiperdia será agregado a esse sistema e suas informações poderão ser analisadas em bases de dados articuladas com as provenientes do Sistema de Informação H ospitalar.

\section{Jurídica e social}

Q16 - LF Atualmente, vários processos, desencadeados por portadores de diabetes, têm recebido parecer favorável da justiça, principalmente quanto ao uso de material para automonitoração ou de insulinas especiais, que sempre são de al to custo. Tendo em vista a limitação dos recursos financeiros dos municípios, 0 atendimento dessas ordens judiciais representa o não atendimento de necessidades básicas de maior parcela de pacientes.

Como o Poder Judiciário pode ser conscientizado dessas repercussões?
Como os municípios poderiam contestar essas exigências legais?

JS De fato, os insumos para automonitoramento da glicemia e insulinas especiais (as de ação ultra-rápida e a insulina glargina de ação lenta), além da bomba de insulina, vêm sendo motivo de muitas demandas judiciais para os municípios e para o MS também. Já existe parecer técnico da área específica de controle de HA e DM contrário à distribuição indiscriminada dessas insulinas especiais de altíssimo custo e da bomba, incompatíveis com os procedimentos e necessidades das ações de saúde pública, que têm de atender milhões de pessoas. Essa decisão foi aval izada pelas sociedades científicas da área. No entanto, foi sugerida a inclusão no Programa de M edicamentos Excepcionais com protocolos e fluxo específico, entendendo que, por ser fruto de um avanço tecnológico e científico, deve ter a possibilidade de estar disponível a quem, de fato, pode beneficiar-se dele por ter tentado todas as demais alternativas de tratamento sem 0 adequado resultado. Estamos estudando essa questão juntamente com a área de Assistência Farmacêutica e deveremos ouvir os especialistas da área. Quanto aos insumos para automonitoramento, vamos nos adequar com o surgimento das leis específicas junto com estados e municípios, mas sabemos que a glicemia é exame que já é feito nas unidades básicas e centros de especialidade para controle e monitoramento do paciente com diabetes.

Comentário LF Não existe proposta de conscientização do Poder Judiciário sobre as repercussões das decisões. Além disso, para as prefeituras se defenderem dessas decisões existe um custo que não é previsto nos orçamentos dos municípios. Em alguns governos anteriores, existiam comitês assessores, com representantes de sociedades científicas, universidades e do governo, que elaboravam critérios para o uso de medicações ou equipamentos especiais. O u seja, definir quem de fato necessita e quais os passos ou etapas a serem seguidas. Com base nessas normas, poderiam ser estabelecidas cotas regionais e se programar o orçamento.

\section{Convênios médicos}

Q17 - LF 0 portador de diabetes deve pagar mais por um convênio médico?

JS No âmbito da saúde suplementar enfrentamos ainda muitos problemas, sobre os quais a nova direção da Agência Nacional de Saúde está 
se debruçando. Destacaríamos a manutenção de grande contingente de usuários com contratos anteriores à atual legislação que não têm garantias de atendimentos em inúmeras situações (está sendo construído um movimento de migração para contratos novos com mais garantias estabelecidas) , a ausência de contratos com serviços e profissionais (estão em curso medidas para sua efetivação) e falta de efetividade do ressarcimento ao SUS, diante das ações judiciais e ineficiência do sistema centralizado de ressarcimento montado na gestão anterior do M inistério da Saúde (existem estimativas de que $15 \%$ dos pacientes que fazem hemodiálise pelo SUS têm algum tipo de plano ou seguro saúde). É óbvio que a discriminação de clientela deve ser constrangida e coibida tanto no SUS quanto na saúde suplementar.

Comentários LF Concordo com a resposta. Além disso, a regulamentação sobre os convênios tem sido motivo de freqüentes mudanças, que nem sempre visam aos interesses dos segurados. As decisões quanto ao ressarcimento do SUS pelos atendimentos aos segurados deveriam merecer maior atenção e agilidade, tanto pelo M inistério da Saúde quanto pelo Poder Judiciário.

\section{Comentários finais (IL)}

As poucas e descontinuadas experiências passadas - sucessos ou fracassos - sobre as políticas e programas das DCNT no Brasil não foram, de fato, comentadas, talvez por causas relacionadas a mudanças assistenciais ocorridas em cada período de governo, desde a implementação do Sistema Único de Saúde. A atuação do SUS tem sido inexpressiva na promoção à saúde e na prevenção das DCNT. Neste sentido, até há muito pouco tempo o direcionamento era para a detecção precoce do câncer de colo do útero e do câncer de mama, incluindo-se posteriormente a prevenção do câncer de pele e abordagens sobre fatores de risco, especialmente referentes ao tabagismo e exposição aos raios solares, visando à prevenção primária. Muito do que se comenta sobre obesidade, hiperten são, hipercolesterolemia ou diabetes fica na dependência da mídia, sempre acompanhando a realidade de outros países ou modismos vigentes. Nem por isso, experiências incipientes e pontuais nos últimos 40 anos perderam a sua importância histórica na saúde pública do País, como as iniciativas da antiga Fundação SESP.
Os questionamentos dos entrevistadores e as respostas do entrevistado em relação ao tempo presente permitem conhecer parte do que vem sendo realizado, como Programa de Governo, para a hipertensão e para o diabetes no Brasil, as políticas que os norteiam, bem como ações fora do âmbito do M inistério da Saúde, demandando ações judiciais para tratamentos essenciais e prioritários para o diabetes.

As respostas do entrevistado, na quase totalidade, apontam propostas delineadas para 0 futuro, algumas provavelmente a serem concretizadas a muito longo prazo. Inclui-se nas respostas a indisponibilidade de tratamentos mais onerosos sobre o Sistema de Saúde, e que são exatamente aqueles que propiciariam redução de incapacidade/invalidez, uma vez a doença já presente. Exemplos claros, expressos na entrevista, estão nos questionamentos sobre o uso do tratamento a laser para prevenção da cegueira de diabéticos, para os quais uma única sessão do procedimento é insuficiente, bem como a não disponibilização do material essencial ao autocontrole domiciliar da glicemia. Outras indisponibilidades, também direcionadas para prevenção terciária, em diabéticos, centram-se na prevenção das amputações. Além de social e economicamente vantajosa, a prevenção da amputação ou a sua reabilitação são possíveis a partir do diagnóstico precoce e tratamento da isquemia vascular periférica e da inclusão sistemática do suprimento de órteses e próteses para os portadores do pé diabético ou para os já amputados.

No confronto entre discrepâncias das prioridades para Aids e das prioridades para a hipertensão (questionamento de um dos entrevistadores), como também para o diabetes e outras DCNT, que entram com maior peso na composição dos atuais $66 \%$ da carga de doença no Brasil, uma importante discussão implicaria as pressões de grupos sociais capazes de motivar respostas governamentais favoráveis ( próAids), de elevado custo financeiro, com repercussões sobre a sociedade, mesmo que tais grupos sejam representados por pequena parcela da população.

Esse tipo de pressão não emerge dos miIhões de brasileiros que convivem com a hipertensão e outras DCNT, nem é influenciada pelos milhares de mortes anuais por esses grupos de doenças. Seus custos hospitalares e aqueles com licenças para tratamento, com aposentadorias precoces por incapacidades ou invalidez e com pensões por mortes prematuras, além de 
uma elevada soma de custos indiretos, parecem não exercer pressões sobre os gastos com a Saúde e com a Seguridade Social. Excetuando-se os casos de Aids congênita e aqueles adquiridos por uso de sangue e derivados impropriamente utilizados, os fatores comportamentais estão entre os maiores determinantes da Aids, assim como das DCNT, mesmo reconhecendo-se que no caso da Aids, a presença do agente vivo (vírus) seja uma condição necessária. Ademais, muitas das DCNT, ao contrário da Aids, estão relacionadas às iniqüidades sociais, desde a vida intra-uterina, como hoje se reconhece.

Acredito ser esta entrevista uma contribuição para avaliações futuras do que se prevê para a redução dos riscos para a hipertensão e diabetes, cobertura assistencial em todo o país, e redução das suas conseqüências. Considere-se nesse contexto a adesão do M inistério da Saúde do Brasil à Estratégia Global de Alimentação Saudável e Atividade Física, proposta pela O rganização Mundial da Saúde, e tema principal da 56a Conferência M undial de Saúde em 2004. 